\title{
Present and future variations in Antarctic firn air content
}

\author{
S. R. M. Ligtenberg, P. Kuipers Munneke, and M. R. van den Broeke \\ Institute for Marine and Atmospheric research Utrecht (IMAU) P.O. Box 80000, 3508 TA Utrecht, the Netherlands
}

Correspondence to: S. R. M. Ligtenberg (s.r.m.ligtenberg@uu.nl)

Received: 20 December 2013 - Published in The Cryosphere Discuss.: 15 January 2014

Revised: 15 July 2014 - Accepted: 27 July 2014 - Published: 17 September 2014

\begin{abstract}
A firn densification model (FDM) is used to assess spatial and temporal (1979-2200) variations in the depth, density and temperature of the firn layer covering the Antarctic ice sheet (AIS). A time-dependent version of the FDM is compared to more commonly used steady-state FDM results. Although the average AIS firn air content (FAC) of both models is similar $(22.5 \mathrm{~m})$, large spatial differences are found: in the ice-sheet interior, the steady-state model underestimates the FAC by up to $2 \mathrm{~m}$, while the FAC is overestimated by $5-15 \mathrm{~m}$ along the ice-sheet margins, due to significant surface melt. Applying the steady-state FAC values to convert surface elevation to ice thickness (i.e., assuming flotation at the grounding line) potentially results in an underestimation of ice discharge at the grounding line, and hence an underestimation of current AIS mass loss by $23.5 \%$ (or $16.7 \mathrm{Gt} \mathrm{yr}^{-1}$ ) with regard to the reconciled estimate over the period 1992-2011. The timing of the measurement is also important, as temporal FAC variations of $1-2 \mathrm{~m}$ are simulated within the $33 \mathrm{yr}$ period (1979-2012). Until 2200, the Antarctic FAC is projected to change due to a combination of increasing accumulation, temperature, and surface melt. The latter two result in a decrease of FAC, due to (i) more refrozen meltwater, (ii) a higher densification rate, and (iii) a faster firn-to-ice transition at the bottom of the firn layer. These effects are, however, more than compensated for by increasing snowfall, leading to a 4-14\% increase in FAC. Only in meltaffected regions, future FAC is simulated to decrease, with the largest changes $(-50$ to $-80 \%)$ on the ice shelves in the Antarctic Peninsula and Dronning Maud Land. Integrated over the AIS, the increase in precipitation results in a similar volume increase due to ice and air (both $\sim 150 \mathrm{~km}^{3} \mathrm{yr}^{-1}$ until 2100). Combined, this volume increase is equivalent to a surface elevation change of $+2.1 \mathrm{~cm} \mathrm{yr}^{-1}$, which shows that variations in firn depth remain important to consider in future mass balance studies using satellite altimetry.
\end{abstract}

\section{Introduction}

The most common method to determine the effect of climate change on the Antarctic ice sheet (AIS) is to calculate the change in mass over time. Due to its remoteness, adverse climate conditions, and sheer size, it is difficult to measure the mass balance of the AIS directly. Over the last few decades, the introduction of satellite and airborne remote sensing techniques has increased the understanding of ice-sheet processes and led to more accurate mass balance estimates. Three methods involving satellite remote sensing are generally used for ice-sheet mass balance calculations: (i) the mass-budget method (e.g., Rignot et al., 2008), (ii) the gravimetric method (e.g., Velicogna, 2009), and (iii) the volumetric method (e.g., Davis et al., 2005). The first method calculates the mass input and output of the ice sheet directly by subtracting the ice discharge over the grounding line from the surface mass balance (SMB) of the grounded ice sheet. The second method directly measures mass variations in the earth's gravity field, from which ice mass changes can be deduced if a correction is applied for all other mass-varying processes (e.g., ocean tides and bedrock movement). The third method measures the change in ice volume from surface elevation changes. These variations can be converted into ice mass change if the density of the material at which the volume change takes place is known.

To obtain meaningful mass balance estimates, all three remote sensing techniques require corrections for surface processes, such as precipitation anomalies (Horwath et al., 2012), firn pack changes (Zwally and Li, 2002; Helsen et al., 2008), or bedrock movement by glacial isostatic adjustment (GIA, Peltier, 2004; Whitehouse et al., 2012). These corrections are often provided by models that simulate the aforementioned processes. While the three methods are based on different principles and measure different quantities, they 
give reasonably consistent results for the mass balance of the Greenland and Antarctic ice sheets over the past two decades (Shepherd et al., 2012).

All three methods depend on a correct estimation of the mass and volume of the firn layer. This paper focuses on firn layer variations and their influence on mass balance measurements. Knowledge of variations in the firn volume and mass is a necessity for the mass-budget method and the volumetric method, and it aids in the interpretation of gravity measurements. Firn-induced surface elevation changes, as simulated by a firn densification model, are used to correct remotely sensed surface elevation changes in order to obtain the mass loss/gain of the glacier ice underneath (e.g., Zwally and Giovinetto, 2011; Sørensen et al., 2011; Pritchard et al., 2012). Firn pack variations also need to be considered for the mass budget method. Ice thickness measurements that are used to calculate ice discharge over the grounding line (e.g., Rignot et al., 2011), must be corrected for the amount of air in the firn column to prevent an overestimation of the mass flux (Van den Broeke et al., 2008).

The firn air content (FAC) of a firn column depends on both firn layer depth and density; these, in turn, are governed by the local surface climate conditions (Ligtenberg et al., 2011). Due to the large spatial heterogeneity in climate conditions over the AIS, the FAC also exhibits a large variability. In locations with net ablation, no firn layer is present, while favorable local climate conditions can lead to a FAC of more than $40 \mathrm{~m}$ (Van den Broeke, 2008; Ligtenberg et al., 2011). These FAC values are usually obtained from a steady-state firn density profile that is calculated with the long-term average temperature and accumulation (Herron and Langway, 1980; Barnola et al., 1991; Zwally and Li, 2002). Until now, ice thickness observations have been corrected with either a constant FAC value (e.g., Rignot and Jacobs, 2002) or with a spatially varying pattern, but are constant in time (e.g., Depoorter et al., 2013; Fretwell et al., 2013). Either way, temporal variations in firn layer density and thickness are neglected.

Due to large seasonal and inter-annual variations in the Antarctic climate, temporal variations in firn pack characteristics can be significant (Ligtenberg et al., 2012). At higher temperatures, the densification rate of firn increases, i.e., near-surface firn densifies quicker in summer than in winter (Herron and Langway, 1980). This also implies that a snowfall event in winter/summer deposits a firn layer with lower/higher density. When surface melt occurs in summer, the local refreezing of meltwater in the firn pore space is a very efficient densification process. Steady-state firn solutions are based on dry-firn compaction and do not take melt into account (Herron and Langway, 1980; Ligtenberg et al., 2011). In higher parts of the AIS, constituting 90\% of its area, this is a valid assumption as surface melt does not occur (Lenaerts et al., 2012). However, along the coasts and on the fringing ice shelves, annual surface melt can be significant and cause large seasonal variations in firn character- istics. Furthermore, the grounding line of the AIS is often located in these low-elevation areas, making it sensitive to these variations.

This study presents and explains temporal variations in FAC on the AIS, as well as their climatic cause. We do this for the present day (1979-2012), as well as for future variations over the next two centuries. We also discuss important implications of this analysis for mass balance estimates of the AIS. First, the firn densification model and its different atmospheric forcing fields will be introduced.

\section{Methods}

\subsection{Firn densification model}

The present-day and future evolution of the Antarctic firn layer are simulated with a one-dimensional, time-dependent firn densification model (FDM). The full details of the FDM are described in Ligtenberg et al. (2011) and will only be briefly summarized here. The current model version is based on Herron and Langway (1980), and subsequent modifications by Zwally and Li (2002), Helsen et al. (2008), and Ligtenberg et al. (2011). It uses the adapted densification equations of Arthern et al. (2010), that were tuned to fit Antarctic firn depth-density observations (Ligtenberg et al., 2011):

$$
\begin{aligned}
& \frac{\mathrm{d} \rho}{\mathrm{d} t}=C \dot{b} \mathrm{~g}\left(\rho_{\mathrm{i}}-\rho(z)\right) e^{\left(\frac{-E_{\mathrm{c}}}{\mathrm{RT}(z)}+\frac{E_{\mathrm{g}}}{\mathrm{RT} \mathrm{T}_{\mathrm{s}}}\right)}, \text { where } \\
& C=0.07(1.435-0.151 \ln (\dot{b})) \text { for } \rho(z)<550 \mathrm{kgm}^{-3}, \\
& C=0.03(2.366-0.293 \ln (\dot{b})) \text { for } \rho(z)>550 \mathrm{kgm}^{-3},
\end{aligned}
$$

where $\dot{b}$ is the average annual accumulation (mm w.e. $\mathrm{yr}^{-1}$ ), $g$ is the gravitational acceleration, $\rho_{i}$ is the ice density $\left(917 \mathrm{~kg} \mathrm{~m}^{-3}\right), R$ is the gas constant, and $E_{\mathrm{c}}$ and $E_{\mathrm{g}}$ are the activation energy constants (Arthern et al., 2010). The density of fresh snow for every location is calculated using the local average surface temperature, accumulation, and wind speed, according to Kaspers et al. (2004). A snowmelt module is included to simulate and calculate simple firn hydrology; the amount of percolation, retention, refreezing and runoff of meltwater. This module uses the simple "tipping-bucket" method (i.e., liquid water is stored in the first available layer and only transported downwards when it exceeds capillary forces), which performs relatively well in comparison with other, more sophisticated firn hydrological methods (Wever et al., 2014). Moreover, most of the Antarctic meltwater refreezes instantly due to the cold firn pack conditions. With the inclusion of firn hydrology, the FDM is capable of simulating firn evolution in both the dry-snow zone and meltaffected regions.

One of the basic principles of the FDM is its "steady-state assumption", i.e., the firn layer is in equilibrium with the local long-term climate forcing. To fulfill this criterion, the 
available climate forcing time series needs to be long enough to represent the long-term average climate. This has been previously done by assuming that the past $33 \mathrm{yr}$ (1979-2012) are a good representation of the Antarctic climate over the last centuries (Ligtenberg et al., 2011, 2012). Indeed, the AIS climate shows no significant trends in the recent past (Monaghan et al., 2006; Bromwich et al., 2011; Lenaerts et al., 2012), making this assumption valid. However, this steadystate assumption is not valid for future simulations (which will be introduced in the next section), and therefore requires small adaptations to the FDM. First, the climate of 1960 1979 is assumed to equal the long-term average climate and serves as spin-up climate for the FDM. Thereafter, the modeled firn layer is allowed to evolve over the period 1980 2199 . Secondly, the annual average surface temperature and accumulation, that are used in the densification equations, are taken as the running average over the last 40 simulation years. This is done to include the effect of the changing climate on firn densification. For example, in 2120 the annual average temperature and accumulation are calculated over the period 2080-2119. Thirdly, the deep-layer temperature ( $>15 \mathrm{~m}$ depth) is allowed to rise with future rising surface temperatures, while the present-day simulation uses a fixed annual average temperature at depth, consistent with the above-described steady-state assumption.

\subsection{Atmospheric forcing}

Output of the regional atmospheric climate model RACMO2 (Van de Berg et al., 2006; Van Meijgaard et al., 2008; Lenaerts et al., 2012) is used as atmospheric forcing of the FDM. At the surface, it is forced with SMB components (precipitation, surface sublimation, surface melt and drifting snow processes), surface temperature, and $10 \mathrm{~m}$ wind speed.

\subsubsection{Present-day climate}

For the present-day simulation (August 1979 to August 2012), 6-hourly RACMO2 output of Lenaerts et al. (2012) is used. The same forcing was previously used for present-day FDM simulations (Ligtenberg et al., 2011, 2012). To obey the steady-state assumption, and to create a realistic initial firn profile, the same procedure as in Ligtenberg et al. (2011) is used; the FDM is run iteratively until the complete firn layer is refreshed (100-5000 yr), after which the final simulation starts. The spatial resolution of the FDM is $27 \mathrm{~km}$, equal to that of the forcing model, RACMO2. The temporal resolution of present-day FDM output is 2 days for surface properties and every week for depth-density profiles.

\subsubsection{Future climate}

For the future simulation, we used the same approach and data as Kuipers Munneke et al. (2014). This approach is based on a future climate simulation with RACMO2, forced by global climate model data (HadCM3) using the A1B emission scenario (Ligtenberg et al., 2013). To extend the climate forcing prior to the RACMO2 simulation (1960-1979), the Antarctic climate is reconstructed using an "analogue method", based on historical observational temperatures and accumulation fields form Monaghan et al. (2008). In short, one starts with finding the nearest monthly average temperature in the 1980-1999 period compared to January 1960, and one copies the daily climate values (e.g., temperature, precipitation and surface melt) from that month into January 1960. This is subsequently done for every month in the 1960-1979 period and for every RACMO2 grid point. This way, a synthetic daily climate is reconstructed, while spatial variations are preserved and sub-monthly variability is introduced. Afterwards, the daily values of 1960-1979 are bias-corrected for the introduced difference between the 1960-1979 and 1980-1999 average climates. Finally, a 40 yr average climate without trend is obtained. A more detailed description and discussion of this procedure is found in the appendix of Kuipers Munneke et al. (2014).

The period 1960-1979 is used as spin-up period and the FDM is run iteratively as often as needed to refresh the complete firn layer, after which the final $240 \mathrm{yr}$ simulation starts (1960-2200). It should be noted that the FDM future simulation uses synthetic climate data from a global climate model, in contrast to re-analysis data for the present-day run, making a direct comparison with the present-day simulation impossible; i.e., " 1985 " data from the future simulation are not comparable with real 1985 data from the present-day simulation. Therefore, only the long-term averages (1979-2012 for the present-day simulation and 1960-1999 for the future simulation) are compared. For computational efficiency, the RACMO2 climate simulation was performed on a $55 \mathrm{~km}$ horizontal resolution, which is therefore also the spatial resolution of the FDM future simulation. The temporal resolution of future FDM output is 2 days for surface properties and 1 month for depth-density profiles.

\subsection{Firn air content}

The firn air content (FAC) is a measure for the pore space fraction of the firn layer and is defined as the change in thickness (in meters) that occurs when the firn column is compressed to the density of glacier ice:

$\mathrm{FAC}=\int_{z_{s}}^{z\left(\rho_{i}\right)}\left(\rho_{i}-\rho(z)\right) \mathrm{d} z$,

where $\rho_{i}$ is the ice density, here assumed to be $910 \mathrm{~kg} \mathrm{~m}^{-3}$, and $z_{s}$ and $z_{\rho_{i}}$ indicate the surface and the depth at which the ice density is reached, respectively. Often $917 \mathrm{~kg} \mathrm{~m}^{-3}$ is taken as the ice density; here, we use a slightly lower number, as the density in the FDM will never exactly reach $917 \mathrm{~kg} \mathrm{~m}^{-3}$ due to the asymptotic nature of Eq. (1). The definition of the FAC (following Holland et al., 2011) is slightly 

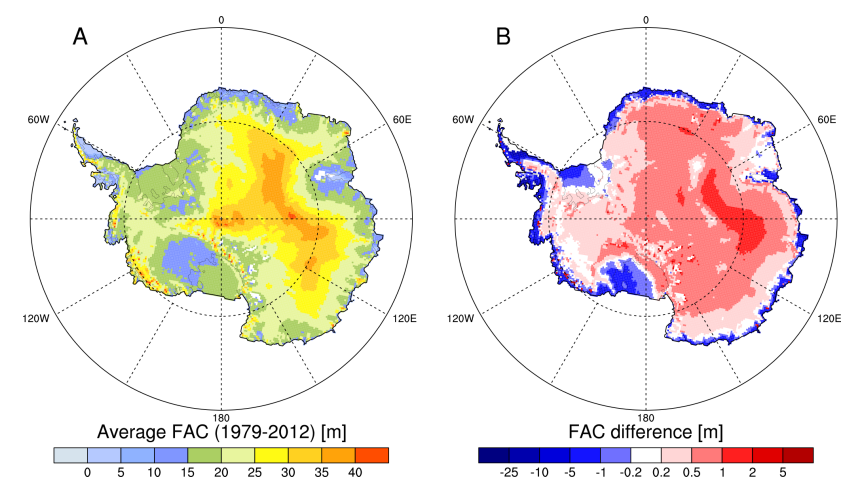

Figure 1. Average firn air content (FAC) for 1979-2012 (a), simulated by the time-dependent model, and the difference between (a) and the steady-state model (b), from Ligtenberg et al. (2011) (Fig. 8a). The FAC represents the height difference of the column (in meters) that remains when the firn layer is compressed to ice density (here assumed to be $910 \mathrm{~kg} \mathrm{~m}^{-3}$ ).

different to the one commonly used in ice core research, where air content is expressed as air volume per gram of ice (Martinerie et al., 1994). This latter definition is more convenient when analyzing vertical differences in air content, but since this paper focuses on the air content of the entire firn column, the integrated firn air content as in Eq. (4) is used. Throughout the manuscript, the effect of liquid water stored in the firn pore space is neglected when calculating the FAC. Most meltwater on Antarctica refreezes immediately, so no significant liquid water bodies are expected.

\section{Results}

\subsection{Present-day variations}

Figure 1a shows the average FAC for 1979-2012, as simulated by the present-day FDM simulation. High values are found on the East Antarctic plateau, where firn densification is a slow process due to the low temperatures. High values are also found at isolated spots in mountainous regions and along the coast, particularly in West Antarctica, where the highest accumulation rates of the AIS are recorded (Van den Broeke et al., 2006; Lenaerts et al., 2012). Due to these high accumulation rates, the firn is buried quickly and has less time to densify, leading to a thick firn layer with a significant amount of pore space. Low FAC values are found in regions with a relatively warm and dry climate. Here, fresh snow is buried more slowly, and the high temperatures enhance firn densification. The Siple Coast $\left(82^{\circ} \mathrm{S}\right.$ and $\left.140^{\circ} \mathrm{W}\right)$ and the Lambert Glacier catchment $\left(73^{\circ} \mathrm{S}\right.$ and $\left.70^{\circ} \mathrm{E}\right)$ are examples of regions with this type of climate. Surface melt has a significant effect on producing low FAC $(<15 \mathrm{~m})$ in coastal areas and on the ice shelves. On the two largest Antarctic ice shelves (IS), the Ross IS and Filchner-Ronne IS, higher FAC values are found due to their southerly locations, associated with lower tem-
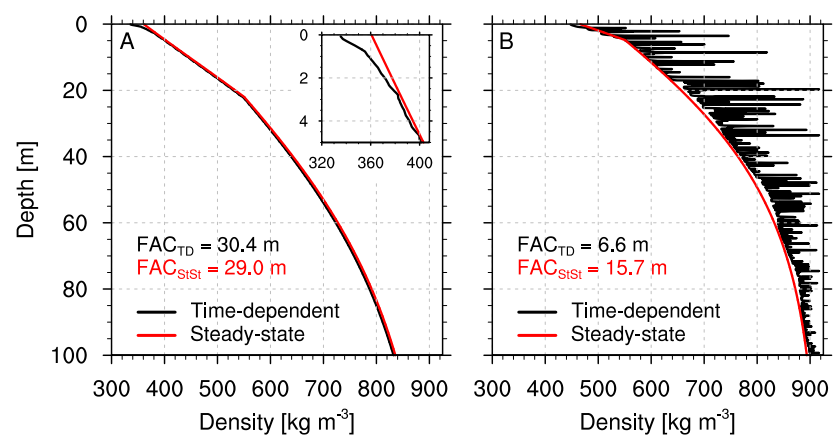

Figure 2. Typical firn density profiles for two locations in Antarctica; one without snowmelt (a) on the East Antarctic plateau $\left(85^{\circ} \mathrm{S}\right.$, $84^{\circ} \mathrm{E}$ ) and one with significant summer snowmelt (b) near George VI ice shelf $\left(73^{\circ} \mathrm{S}, 67^{\circ} \mathrm{W}\right)$. For both locations, the steady-state ("StSt", red) and time-dependent ("TD", black) solutions of the FDM are shown, with in (a) an inset showing the first $5 \mathrm{~m}$, as well as the firn air content (FAC) for both profiles.

peratures and weaker melt. The West Antarctic ice shelves receive high annual accumulation rates that partly mask the melt signal. The white areas indicate locations where no firn layer is simulated as a consequence of annual sublimation and/or melt exceeding annual accumulation in the RACMO2 forcing. These locations coincide reasonably well with observed blue ice areas, i.e., locations where no firn layer is present (Scambos et al., 2012; Das et al., 2013).

The general spatial pattern of the average FAC from the time-dependent FDM solution (Fig. 1a) is similar to that of the steady-state FDM (Fig. 8a in Ligtenberg et al., 2011), and the ice-sheet average is identical for both models at $22.5 \mathrm{~m}$. However, Fig. 1b shows that substantial spatial differences exist between the two. In the AIS interior, the time-dependent FDM simulates slightly more firn air, with the largest positive differences (as large as $2 \mathrm{~m}$ ), occurring near the domes of the East Antarctic plateau. The positive differences are simulated in the part of Antarctica where no surface melt occurs, and they are caused by a bias correction in the surface density used in the steady-state FDM (Ligtenberg et al., 2011), introduced to simulate the majority of the depth-density profile (i.e., the depth at which the $550 \mathrm{~kg} \mathrm{~m}^{-3}$ and $830 \mathrm{~kg} \mathrm{~m}^{-3}$ density levels are reached) similarly in both models (Fig. 2a). A disadvantage of this bias correction is that the density in the top $\sim 2 \mathrm{~m}$ of the firn layer is overestimated in the steady-state solution, causing a lower total air content for the firn column. In this part of the firn column, the seasonal temperature variations are large and, in particular, the higher firn temperatures in summer and autumn cause a quicker density increase with depth than is simulated by the steady-state solution. In the remainder of the firn column, both density profiles are virtually indistinguishable (Fig. 2a). 

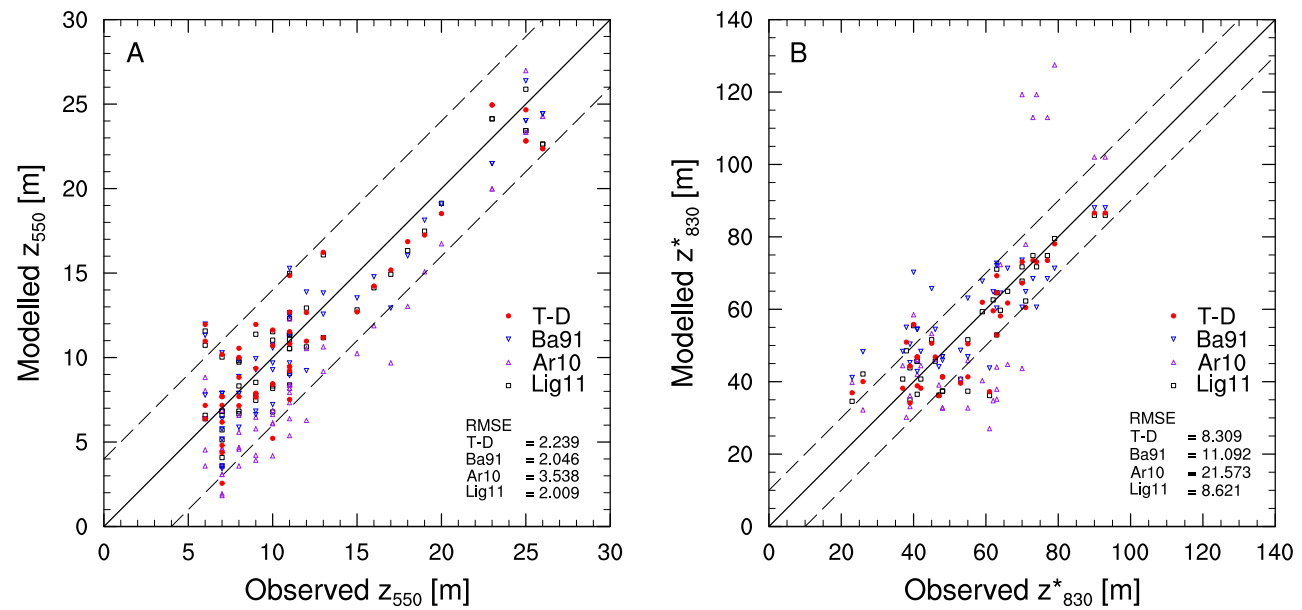

Figure 3. Comparison of observed and modeled depths of two critical density levels: $550 \mathrm{~kg} \mathrm{~m}^{-3}$ (a) and $830 \mathrm{~kg} \mathrm{~m}^{-3}$. Observed depths are from 48 firn cores across the Antarctic ice sheet (Van den Broeke, 2008), and model simulations from the steady-state models of Barnola et al. (1991) (Ba91, blue downward triangle), Arthern et al. (2010) (Ar10, purple upward triangle) and Ligtenberg et al. (2011) (Lig11, black square) and the time-dependent simulation used here (red filled circles) are shown. Note that $z_{830}^{*}$ represents the depth between the 550 and $830 \mathrm{~kg} \mathrm{~m}^{-3}$ density level and not the true depth of the $z_{830}$ (same as in Ligtenberg et al., 2011).

The latter statement is accentuated by the comparison of depth-density characteristics with in situ observations from dry firn cores and earlier model results. Figure 3 shows the depth of two critical density levels (550 and $830 \mathrm{~kg} \mathrm{~m}^{-3}$ ), as observed in 48 firn cores (Van den Broeke, 2008), compared to four model simulations (steady-state simulations by the Barnola et al. (1991), Arthern et al. (2010), and Ligtenberg et al. (2011) models and the time-dependent FDM simulation used here). The time-dependent FDM results show good agreement with observed depths ( $z_{550}$ and $\left.z_{830}\right)$; both the magnitude and range are similar. Moreover, the steadystate (black square) and time-dependent (red circle) FDM results agree well for almost all locations. The difference between both is generally below $2 \mathrm{~m}$, which is lower than the uncertainty in most firn core measurements (Van den Broeke, 2008). The slightly higher/lower root mean squared error (RMSE) for the $550 / 830 \mathrm{~kg} \mathrm{~m}^{-3}$ density level, compared to Ligtenberg et al. (2011), indicates that the surfacedensity bias correction introduces a small error into the density profile of the steady-state simulations. The difference in FAC between the two FDM simulations originates from the bias correction in surface density, and can be separated into the obvious mismatch in the density near the surface and a smaller mismatch in the entire depth-density profile. The seasonal differences in temperature are only felt in the top 3-5 $\mathrm{m}$ and can cause FAC differences up to $0.2 \mathrm{~m}$ (note: the FAC difference in the top $3 \mathrm{~m}$ in Fig. $2 \mathrm{a}$ is $0.04 \mathrm{~m}$ ). The second process is more important, as it affects the entire firn column. For example, a mismatch of $5 \mathrm{~kg} \mathrm{~m}^{-3}$ in the entire firn column (100-120 m) leads to a FAC difference on the order of $0.5 \mathrm{~m}$. For locations with significant melt, the effect of this bias correction is generally smaller than for no-melt locations, although it is difficult to quantify. Especially the mismatch due to the second process is smaller because of meltwater refreezing and the subsequently higher firn density.

Along the margins of the AIS, the time-dependent FDM simulates significantly less FAC than the steady-state FDM (Fig. 1b). These negative differences are an order of magnitude larger than the positive differences in the ice-sheet interior (note the skewed color bar in Fig. 1b) and are mainly caused by significant melt. Refreezing of meltwater in the firn is a very effective densification process, which rapidly reduces the FAC (Fig. 2b). Surface melt is not taken into account in the steady-state FDM because of its large seasonal and inter-annual variability. Figure $2 \mathrm{~b}$ shows the difficulty of defining a steady-state firn density profile for locations with substantial melt, due to the uneven distribution of high and low density layers that move downward with time. In locations with occasional melt, such as the Filchner-Ronne IS and Ross IS regions, the difference between the models is relatively small: $1-2 \mathrm{~m}$. In contrast, differences in the Antarctic Peninsula can be as large as $20 \mathrm{~m}$, caused by large summer melt rates.

When calculating the total mass of the AIS from surface elevation observations (e.g., Fretwell et al., 2013), the difference between the steady-state and time-dependent FAC is negligible, as both ice-sheet averages are similar. However, for individual locations, the difference in firn air correction can be as large as $80 \%$. Coincidentally, the largest FAC deviations are found in locations where ice thicknesses are relatively small (coastal regions and ice shelves). This is even more relevant, because ice thickness at the grounding line is an important quantity in mass balance studies of both the 


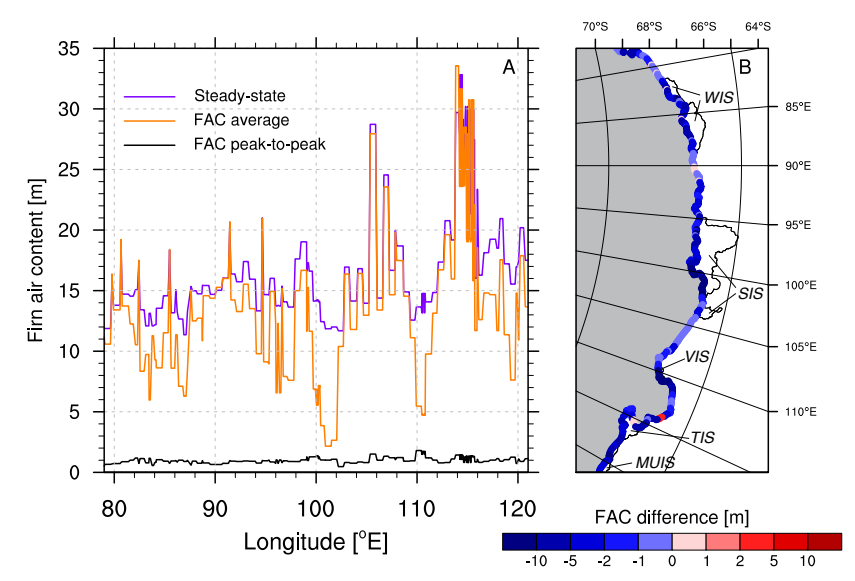

Figure 4. Firn air content (FAC) along part of the grounding line in East Antarctica $\left(78-122^{\circ} \mathrm{E}\right.$, projected as (a) a function of longitude $\left({ }^{\circ} \mathrm{E}\right)$, and (b) as a map. In (a), the FAC from the steady-state (purple) and time-dependent (orange) models, as well as the peak-topeak difference (black) in the time-dependent model, are shown. In (b), the average difference between both models is shown. Names of ice shelves: West Ice Shelf (WIS), Shackleton Ice Shelf (SIS), Vincennes Ice Shelf (VIS), Totten Ice Shelf (TIS), and Moscow University Ice Shelf (MUIS).

grounded ice sheet (e.g., Rignot et al., 2011) and ice shelves (e.g., Depoorter et al., 2013; Rignot et al., 2013). Combined with the local ice velocity, it determines the ice discharge over the grounding line. A systematic error in the FAC at the grounding line directly affects the ice thickness and therewith the ice discharge estimate. Figure 4 shows the difference in FAC between both models along a part of the grounding line in East Antarctica $\left(80-120^{\circ} \mathrm{E}\right)$. The average timedependent FAC $(13.6 \mathrm{~m})$ is lower than the steady-state FAC $(17.2 \mathrm{~m})$, with the largest differences simulated where ice shelves are formed: $82-87^{\circ} \mathrm{E}$ (West IS), $94-102^{\circ} \mathrm{E}$ (Shackleton IS), $110-112^{\circ} \mathrm{E}$ (Vincennes IS), and $115-120^{\circ} \mathrm{E}$ (Totten IS and Moscow University IS). These locations are often situated lower than the neighboring parts of the grounding line and are therefore more susceptible to surface melt.

Averaged over the entire AIS grounding line, the FAC simulated by the time-dependent FDM is $2.70 \mathrm{~m}$ lower than simulated by the steady-state FDM, which is only $0.7 \%$ of the total ice-equivalent thickness at the grounding line $(371 \mathrm{~m}$, from Fretwell et al., 2013). But since ice thickness, ice discharge, and ice-sheet mass balance are linearly related to one another, a FAC difference directly affects the current mass balance estimate $\left(-71 \pm 53 \mathrm{Gt} \mathrm{yr}^{-1}\right.$, by Shepherd et al., 2012). This ice-sheet mass balance is only a fraction (3.1\%) of the total ice discharge $\left(\sim 2300 \mathrm{Gt} \mathrm{yr}^{-1}\right.$, by Rignot et al., 2011), as it is the residual of two large, and almost equal, values: the ice discharge and the SMB. This implies that the $0.7 \%$ increase in ice discharge, due to the FAC difference, leads to a $23.5 \%$ increase (or $16.7 \mathrm{Gt} \mathrm{yr}^{-1}$ ) in the current mass loss estimate of the AIS.
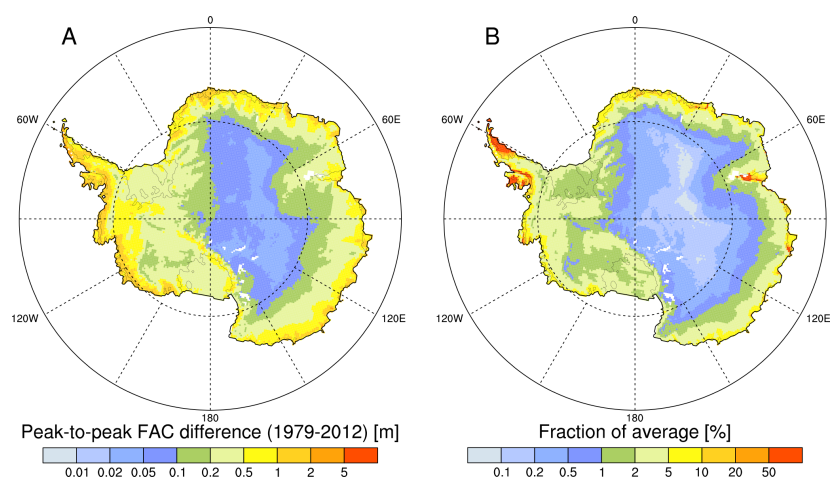

Figure 5. The (a) absolute and (b) relative peak-to-peak variations in firn air content (FAC) in the time-dependent FDM simulation over the 1979-2012 period. The relative difference is compared to the average FAC from Fig. 1a.

In Fig. 4a, also the peak-to-peak FAC difference (i.e., difference between maximum and minimum FAC in the 19792012 period) as simulated by the time-dependent FDM is shown. Large differences indicate that seasonal and interannual climate variations cause large temporal variations in FAC. This means that, depending on the timing of the observation, the firn-layer thickness and its air content could differ from the average value. Along the East Antarctic part of the grounding line (Fig. 4a), this difference is rather constant between $0.5-1.5 \mathrm{~m}$. Depending on the timing of the observation, this introduces additional uncertainty in FAC along the grounding line.

Figure 5 shows the spatial distribution of the absolute and relative peak-to-peak difference in FAC (Fig. 1a). On the East Antarctic plateau, the peak-to-peak differences are small $(<0.2 \mathrm{~m})$, due to a combination of low accumulation rates, low temperatures, and a lack of surface melt. Since the average FAC is large (Fig. 1a), the relative variations are small $(<1 \%)$. In coastal areas, temporal variations are much larger due to both the occurrence of melt and higher accumulation rates. A coastal band of $\sim 150 \mathrm{~km}$ wide experiences peak-topeak differences of $1-3 \mathrm{~m}$, with the highest values $(\sim 3 \mathrm{~m})$ on the western side of the Antarctic Peninsula, due to a favorable combination of extremely high accumulation rates and substantial surface melt. In the Antarctic Peninsula, this leads to relative differences as large as $50 \%$, while other ice shelves mostly show relative differences in the order of 10 $20 \%$. In the remaining coastal areas, the relative magnitude of the peak-to-peak difference is mostly $5-10 \%$ of the average FAC.

The causes of temporal variations in FAC are threefold: variability in rates of (i) accumulation, (ii) firn densification, and (iii) melt processes. Figure 6 shows the spatial distribution of the relative importance of these three effects. It is clear that accumulation (Fig. 6a) is the main driver of FAC variations, which was already found in earlier studies (Davis et al., 2005; Helsen et al., 2008; Ligtenberg et al., 2012), but 


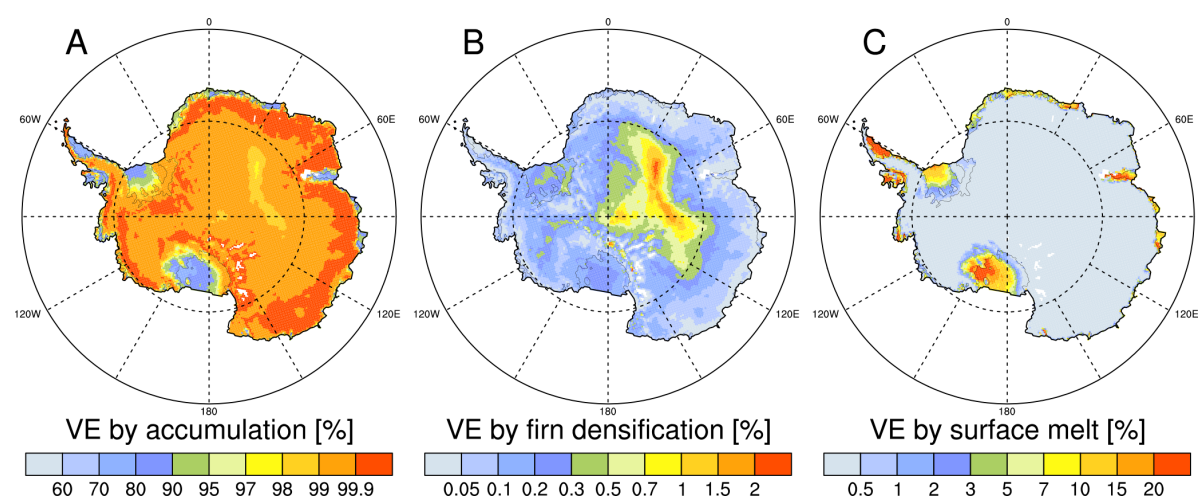

Figure 6. Fraction of firn air content variations (Fig. 5a) explained (VE) by accumulation (a), firn densification (b) and surface melt (c). Note the different scales in (a), (b), and (c).

never quantified. In most parts of the AIS, more than $99 \%$ of the FAC variations are explained by accumulation variability. In the steeper regions of the ice sheet $(\sim 250 \mathrm{~km}$ inland of the coast), where accumulation rates are relatively high, this increases to more than $99.9 \%$. At locations without snowmelt, the remainder of the signal is explained by variations in firn densification, which are caused by sub-surface temperature variations. In reality, variations in overburden pressure also add to firn densification rate variability, but, in the current model equations, this is scaled with the average annual accumulation Eq. (1) and is therefore constant in time. At the highest elevations, where accumulation rates are among the lowest in Antarctica, the highest variance explained by firn densification is found: $\sim 2 \%$ (Fig. $6 \mathrm{~b}$ ). This reflects the fact that firn densification is a relatively constant process; variations are minor due to the near-constant temperature in most of the firn layer. Obviously, the variance explained by surface melt is only present at locations where melt occurs: i.e., the coastal areas and ice shelves (Fig. 6c). The largest values ( $>30 \%$ ) are found on the Antarctic Peninsula ice shelves (Larsen C IS and Wilkins IS), where the largest annual surface melt rates are found. Interestingly, at locations with little melt, but also low accumulation rates (e.g., Siple Coast and Amery IS $\left(70^{\circ} \mathrm{S}\right.$ and $\left.\left.70^{\circ} \mathrm{W}\right)\right)$, the influence of melt on FAC variations is also large. A by-product of melt is that refreezing meltwater increases the firn temperature and therefore increases the firn densification rate. In Dronning Maud Land, for example, the variance explained by firn densification is slightly larger on the ice shelves than on the inland ice sheet due to this effect.

\subsection{Future variations}

The future evolution of the AIS firn layer is simulated with the time-dependent FDM, using RACMO2 climate forcing over the 1960-2200 period at $55 \mathrm{~km}$ horizontal resolution. Figure 7a shows the average FAC at the start of this period (1960-1999), representative for the present-day climate. Therefore, it should be in agreement with the present-day
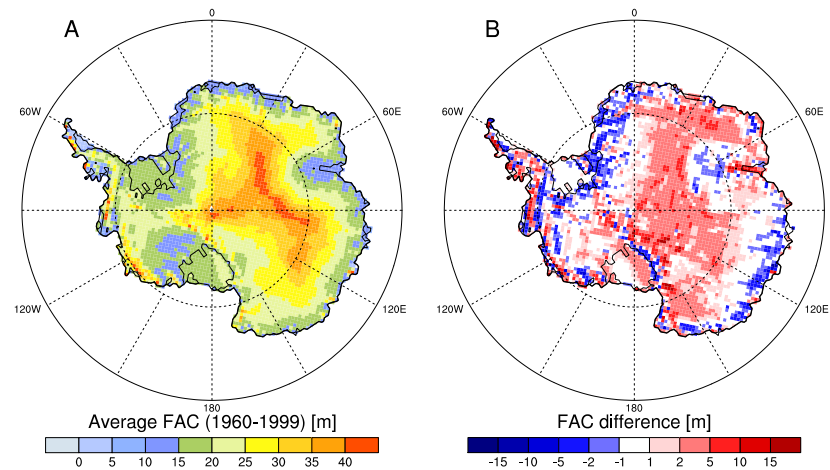

Figure 7. Average firn air content (FAC) for 1960-1999 (a) from the future FDM simulation, and the difference between (a) and average FAC from the contemporary climate simulation (b), interpolated from Fig. 1a to the same grid as in (a).

FAC, as presented in Fig. 1a. The spatial pattern is roughly the same, with the highest values $(>35 \mathrm{~m})$ at the domes of the East Antarctic plateau and lower values $(<15 \mathrm{~m})$ along the coast. Obviously, spatial detail is reduced due to the coarser horizontal resolution, especially in regions with complex topography, such as the Transantarctic Mountains and the Antarctic Peninsula.

Figure $7 \mathrm{~b}$ indicates that most of the FAC differences can be attributed to climate differences caused by the varying topographic detail between the two. Basically, the patterns of high and low accumulation are slightly shifted, leading to subsequent differences in FAC. For example, the Transantarctic Mountains are less pronounced in the coarser resolution of the future simulation, leading to lower accumulation rates and hence smaller FAC. As a consequence, their shielding effect on the East Antarctic interior is also less distinct, resulting in higher accumulation rates and larger FAC values. No negative SMB is simulated in this region, while this is present in the $27 \mathrm{~km}$ simulation (Fig. 1a). Another notable difference is the higher FAC on Amery IS; apparently, the $55 \mathrm{~km}$ grid is too coarse to resolve the complex local topography, and its 


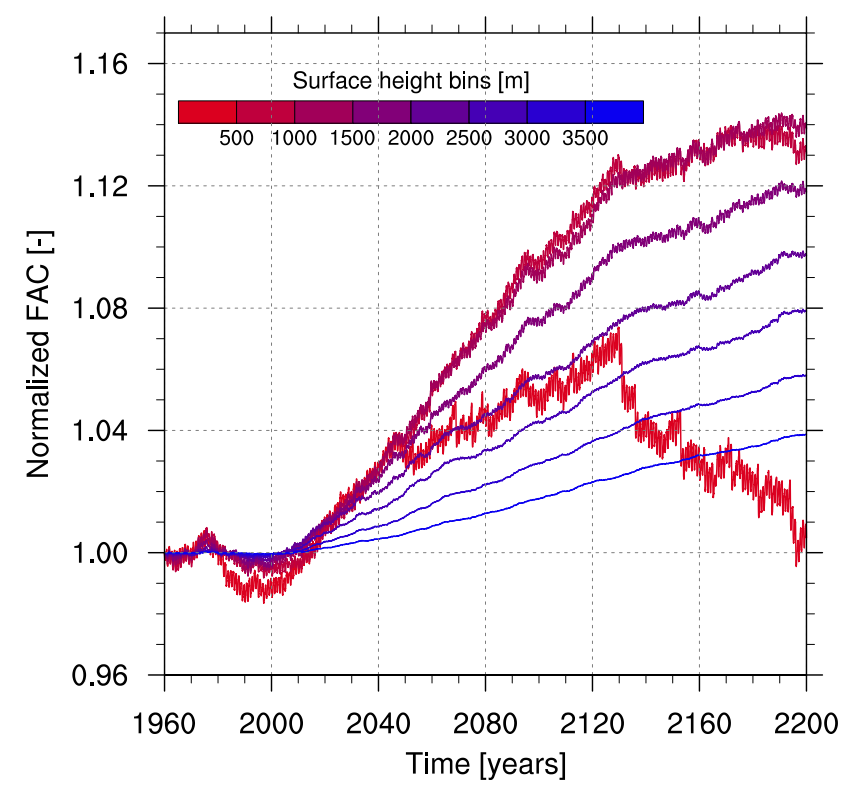

Figure 8. Temporal evolution of firn air content (FAC) in different surface height bins (line color) of the grounded ice sheet. The FAC is normalized using the value of 1 January 1960.

effects on surface melt, that leads to low FAC values in the $27 \mathrm{~km}$ simulation. Looking at the large-scale spatial patterns, the difference is mostly positive in the East Antarctic interior and negative along the coastal margins (Fig. 7b), likely caused by the less steep topography in the coastal areas of the $55 \mathrm{~km}$ grid, resulting in less orographically forced precipitation. On the other hand, more water vapor reaches the interior of the ice sheet and enhances precipitation in this region. Averaged over the entire ice sheet, the average FAC is $23.6 \mathrm{~m}$ (Fig. 7a), compared to $22.5 \mathrm{~m}$ in the $27 \mathrm{~km}$ simulation (Fig. 1a).

When studying the future FAC evolution, anomalies with regards to the 1960-1999 average are more important than the absolute differences outlined above. For example, two firn layers with a different FAC that are in equilibrium with their local climate will react similarly to an increase in precipitation (increase in FAC) or an increase in melt (decrease in FAC). In the next paragraphs, the main focus will therefore be on anomalies in FAC, rather than the absolute values of the change.

Figures 8 and 9 show the spatiotemporal FAC changes in Antarctica over the next two centuries. Averaged over the AIS, there is no trend in FAC over 1960-1979 (Fig. 8), which is consistent with the setup of the FDM; the firn characteristics in 1960 and 1980 are virtually similar, as the model is spun-up iteratively until it is in equilibrium with the 19601979 climate. As the average climate of 1980-1999 is used to scale the average climate of 1960-1979, no large changes are expected during this period. However, especially at lower altitudes, a deviation of a few percent is simulated for 1980-
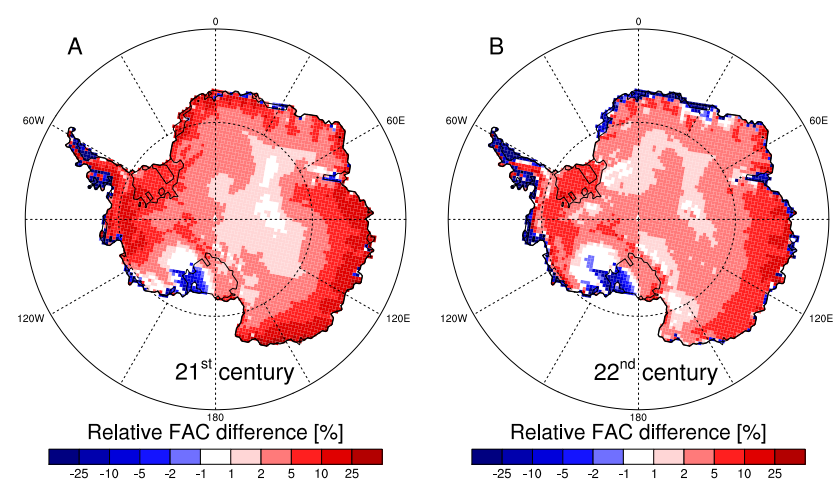

Figure 9. Relative firn air content (FAC) difference over the $21 \mathrm{st}$ (a) and 22nd (b) century. The relative differences are calculated as the difference between the $20 \mathrm{yr}$ averages of 1980-1999 and 20802099, and 2080-2099, and 2180-2199, respectively.

1999, likely caused by the non-linear response of FAC on inter-annual variability in the climatic forcing. The temporal evolution of FAC depends on the timing of inter-annual variations in accumulation (dry or wet), temperature (warm or cold), and surface melt (evenly spread or large pulses). For instance, when starting with a same initial firn layer, the resulting FAC is different when a wet period is followed by a dry period, than vice versa (Helsen et al., 2008). The same accounts for multiple years with large melt rates followed by multiple non-melt years, and vice versa. Averaged over the entire AIS, the relative decrease in FAC in these $20 \mathrm{yr}$ is $0.5 \%$ (Fig. 8b). Much larger changes in FAC are simulated for the 21 st and 22nd centuries in response to increased snowfall and melt. Over the 21st century, the average FAC increases by $4.4 \%(\sim 1.0 \mathrm{~m})$, with the spatial pattern shown in Fig. 9a. Most of the ice-sheet interior shows a uniform increase in FAC. In general, the increase is lower further from the coast; the largest increases are simulated in a wide band along the Wilkes Land and West Antarctic coasts. This pattern is similar to the accumulation increase in the climate forcing (Fig. 10b in Ligtenberg et al., 2013). The largest FAC increases are simulated in the vicinity of Mertz Glacier $\left(68^{\circ} \mathrm{S}, 145^{\circ} \mathrm{E}\right)$, where it increases with $29.6 \%(7.7 \mathrm{~m})$ in $100 \mathrm{yr}$. The FAC increase due to fresh snow is partly counteracted by the faster firn-to-ice transition at the bottom of the firn layer and a faster firn densification rate. In the FDM, both these processes are parameterized with the average annual accumulation, and therefore both are projected to increase in the future.

In the coastal areas of West Antarctica and the Antarctic Peninsula, a significant FAC decrease is simulated, caused by the increase in surface melt in these lower-lying regions. The eastern part of the Ross IS is also expected to experience significantly more melt, resulting in a lower FAC. When the FAC approaches zero, ice shelves can become susceptible to meltwater ponding and hydrofracturing (Kuipers Munneke et al., 2014). 
During the 22nd century, the spatial pattern of FAC change (Fig. 9b) is roughly similar to that of the 21st century (Fig. 9a). Again, there is a distinct and uniform FAC increase in the interior of the ice sheet and a decrease along the margins. However, there are two notable differences. First, the increase over most of the ice sheet is slightly smaller than the 21 st century increase, owing to a less distinct increase in precipitation in the 22nd century. In the second half of the 22nd century, the Antarctic climate stabilizes as the greenhouse forcing of the climate model is set constant at the 2100-level (Ligtenberg et al., 2013). In part, this also explains the flattening of the FAC increase towards the end of the simulation (Fig. 8). Second, along the East Antarctic coast, the decrease in FAC is more pronounced. In particular, the ice shelves in Dronning Maud Land show a significant reduction in FAC (25-40\% or 4-7 m). Also the other East Antarctic ice shelves (e.g., Amery IS, West IS, Shackleton IS) show decreasing firn air values. The relative FAC changes along the West Antarctic coast and in the Antarctic Peninsula are also large, but do not lead to large absolute differences as many of these ice shelves already approach $0 \mathrm{~m}$ by 2100 (Kuipers Munneke et al., 2014).

The future, melt-driven FAC reduction in lower-lying regions is illustrated by the FAC evolution of the $<500 \mathrm{~m}$ height bin in Fig. 8. From 2000 up to 2050, the simulated FAC increase is equal to or slightly larger than the increase in other height bins, indicating that the increase in precipitation during this interval is largest at lower altitudes. Over the next 80 yr (2050-2130), the slope decreases; precipitation is still increasing, but this effect is partly counteracted by a simultaneous increase in surface melt. Around 2135, a couple of strong melt years occur (Ligtenberg et al., 2013) that initiate an abrupt decrease in FAC. Hereafter, a negative trend persists that reduces FAC by $6 \%$ over the last $60 \mathrm{yr}$ of the simulation, and result in a similar FAC amount as in 1960-1979. In all other altitude bins, the FAC increases significantly. The largest relative increases $(\sim 14 \%)$ are found at lower altitudes, in agreement with the largest simulated precipitation increase. Higher up on the AIS, the increase in precipitation becomes smaller, leading to smaller FAC increases. In the highest altitude bin $(>3500 \mathrm{~m}), \mathrm{FAC}$ is simulated to increase by $\sim 4 \%$ over the next two centuries.

These FAC increases can be put in perspective by converting them into volume changes for the entire icesheet. Over the $21 \mathrm{st}$ century, the simulated volume increase is $\sim 150 \mathrm{~km}^{3} \mathrm{yr}^{-1}$, representing the sum of contributions from positive $\left(+158 \mathrm{~km}^{3} \mathrm{yr}^{-1}\right)$ and negative difference grid points $\left(-8 \mathrm{~km}^{3} \mathrm{yr}^{-1}\right)$. During the 22 nd century, the increase summed over the positive grid points is similar $\left(+147 \mathrm{~km}^{3} \mathrm{yr}^{-1}\right)$, but, mainly due to a larger volume change in the negative grid points $\left(-25 \mathrm{~km}^{3} \mathrm{yr}^{-1}\right)$, the total volume change is significantly smaller than during the period 2000-2100. Apart from this increase in firn air due to enhanced precipitation, the mass increase by snowfall itself ( $\sim 150 \mathrm{Gt} \mathrm{yr}^{-1}$, from Ligtenberg et al., 2013) also causes a volume increase: $\sim 150 \mathrm{~km}^{3} \mathrm{yr}^{-1}$. The ratio between the simulated volume increase due to ice and air (more or less $1: 1)$ is lower than expected $(1: 2)$ when solely considering the density of fresh snow $\left(\sim 350 \mathrm{~kg} \mathrm{~m}^{-3}\right)$. This indicates that half of the additional FAC by enhanced snowfall is removed by either snowmelt, increased firn densification, or a faster firn-to-ice transition at the bottom of the firn layer. The combined volume increase from ice crystals and air $\left(\sim 300 \mathrm{~km}^{3} \mathrm{yr}^{-1}\right)$ causes the surface of the AIS to rise with $2.1 \mathrm{~cm} \mathrm{yr}^{-1}$ until 2100 . Therefore, these surface and firn layer effects must be taken into account for future ice-sheet mass balance studies based on volumetric changes. Moreover, this illustrates that knowledge of firn layer behavior and its response to climate variations remains invaluable for a correct interpretation of current and future observations of ice-sheet volume balance.

\section{Discussion}

The results presented here depend strongly on the climate output of the forcing climate model RACMO2. Firn layer density, temperature, and thickness are almost solely determined by the governing climate at its surface. Therefore, a realistic climate that spans over a long enough period is needed to represent a certain reference climate. Based on previous work, RACMO2 produces a realistic Antarctic climate. The simulated SMB corresponds well with $\sim 750$ in situ SMB observations (Lenaerts et al., 2012). Forced with this RACMO2 climate (1979-2011), the steady-state FDM agrees well with depth-density observations from firn cores (Ligtenberg et al., 2011) and simulates firn densities similar to earlier steady-state model simulations (e.g., Zwally and Li, 2002; Van den Broeke, 2008). Seasonal and inter-annual variations in RACMO2 accumulation and subsequent variations in FDM-simulated firn depth compare well with remote sensing observations (e.g., Pritchard et al., 2012; Ligtenberg et al., 2012; Horwath et al., 2012; Medley et al., 2013). Over the $33 \mathrm{yr}$ period, no significant trend is found in the annual average temperature, surface mass balance and melt (Lenaerts et al., 2012; Kuipers Munneke et al., 2012). In combination with a constant climate over the major part of Antarctica during the last century (Monaghan et al., 2006), this provides confidence that the present-day RACMO2 forcing is a realistic reference climate.

In the RACMO2 future climate forcing, more uncertainties are present. The 1980-1999 climate of the global climate model used to force RACMO2 shows a cold and dry bias, when compared to the re-analysis forced RACMO2 simulation (Ligtenberg et al., 2013). This bias is removed from both the present-day period (1980-1999) and the future period (2000-2199) in order to obtain realistic average precipitation and snowmelt values (Kuipers Munneke et al., 2014). The resulting difference in FAC between both present-day simulations is quite small (Fig. 7b), but spatially more significant 
differences occur, which can, for a large part, be explained by the difference in horizontal resolution between both forcings. In Ligtenberg et al. (2013), an assessment of the future climate results shows that the Antarctic snowfall sensitivity (in

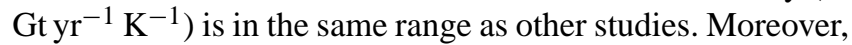
Antarctic precipitation scales linearly with temperature, and since the simulated change is more than three times larger than the bias in the 1980-1999 climate, at least two-thirds of the simulated climate change in RACMO2 is expected to be realistic.

Also, the possible range in future temperature change will produce uncertainty. It was computationally not feasible to perform more than one FDM future simulation for the complete AIS, so a mid-range emission scenario (A1B) was selected. Due to the relatively linear response of precipitation and SMB to temperature increase, the results from this manuscript, in combination with those from Ligtenberg et al. (2013), can be used to scale the temporal firn layer response for different climate scenarios.

The second large source of uncertainty derives from the FDM itself and its ability to simulate temporal evolution of firn temperature and density. The used FDM is based on semi-empirical equations, meaning that uncertainties in in situ measurements are translated into the FDM results. The firn density profile is constrained by three fixed points: (1) surface density, (2) depth at which the density reaches $\rho$ $=550 \mathrm{~kg} \mathrm{~m}^{-3}$, and (3) depth at which the density reaches $\rho=830 \mathrm{~kg} \mathrm{~m}^{-3}$. In the Supplementary Online Material of Depoorter et al. (2013), the uncertainty in FAC is assessed as a combination of these three points, and leads to a total uncertainty in FAC of $\sim 10 \%$. This value is larger than most of the FAC differences between the present-day steady-state and time-dependent simulation (Fig. 1b), indicating that the magnitude of the FAC for a certain Antarctic location inhabits quite a significant uncertainty. However, both simulations use the same set of semi-empirical equations and are therefore subject to the same uncertainty, implying that relative differences between the steady-state and time-dependent results are significant differences.

The FDM is a semi-empirical model and contains a few aspects that are based on the assumption of steady state. Strictly speaking, this makes the model unsuitable for timedependent applications, such as future simulations. The densification equations (Eq. 1) depend on the annual average temperature and accumulation rate. To account for this, we used a running average over the previous $40 \mathrm{yr}$. This time span was chosen because the future climate forcing contains a 40 yr period (1960-1999) that is comparable to the presentday average climate. This way, the steady-state assumption is valid during the entire spin-up period and from 1960 to 1999, during the final simulation, while the future climate change simulation commences in 2000, similar to the set-up of GCM simulations. The choice of this $40 \mathrm{yr}$ running average introduces an additional uncertainty, because it assumes a similar response time for firn layers across the AIS. Also, it assumes that the adjustment of the firn layer to a change in temperature and accumulation is similar. However, an accumulation change is felt instantly as it adds pressure to the top of the firn layer, while it takes time to advect and diffuse a temperature change to greater depths. By using a $40 \mathrm{yr}$ running average window, the increase in annual average temperature and accumulation, and hence the densification rate, is more gradual.

The response time of a shallow firn layer in combination with high annual accumulation rate is much smaller than for thicker firn layers with low accumulation, as it takes less time to fully adjust to a new climate. The response time of the firn layer can be defined as the time needed to advect firn from the surface to the pore-close off depth $\left(z_{830}\right)$, which varies between 20 and $2000 \mathrm{yr}$ across the AIS (Van den Broeke, 2008). However, most of the firn densification occurs in the upper part of the firn layer (10-20 m), so the effective response time will be lower. For example, using the average Antarctic annual accumulation rate $\left(160 \mathrm{~mm} \mathrm{yr}^{-1}\right.$, from Lenaerts et al., 2012), it would take $\sim 60 \mathrm{yr}$ to refresh the upper $20 \mathrm{~m}$ of firn. This is similar to the chosen $40 \mathrm{yr}$ window, making this a reasonable choice. At locations with a higher annual accumulation rate, the firn layer will have a smaller response time and hence a shorter climate memory, while for low-accumulation sites the opposite stands.

The simulated temporal evolution of a firn layer in a changing climate is difficult to evaluate, since hardly any observations of temporal firn changes are available. Moreover, it is challenging to measure the small variations in firn density and depth that result from changes in the climate. Especially when no melt occurs, the increase in firn density, densification rate, and depth are rather subtle and likely to be smaller than the measurement errors.

A definite improvement would be to use a firn model that calculates the firn densification rate using a physical relation between density, overburden pressure, snow grain size, and temperature (e.g., Spencer et al., 2001; Arthern et al., 2010). For instance, in the future simulation, this would make the reaction of the firn layer to additional mass input instantaneous instead of depending on the chosen length of the runningaverage window. Also, in the current FDM the surface density is assumed to be constant, while it is uncertain whether and how the density of fresh snow will change in the future. For the present day, this approximation introduces uncertainty as not every accumulation event is the same, but, on average, the calculated values agree well with observations (Kaspers et al., 2004). The meltwater percolation and refreezing scheme in the current FDM does not include heterogeneous percolation ("piping"), a process that is known to be quite widespread on the Greenland ice sheet (Marsh and Woo, 1984; Harper et al., 2012). Due to this rapid transport of mass and heat to greater depths, the density and temperature profiles are influenced. Apart from some isolated locations on the Antarctic Peninsula, melt amounts across the AIS are generally too small to cause this type of vertical transport in 
Antarctica. However, with future increasing melt rates, this could potentially occur more regularly in warm areas and on ice shelves.

Ultimately, the results are not expected to be greatly influenced by the use of a different model. Most of the interannual(/transient) changes in the present-day(/future) simulations are initiated by variations in the forcing climate (e.g., Fig. 6a), especially accumulation. For the present day, the magnitude and timing of seasonal and decadal climate variations as simulated by RACMO2 (1979-2012) agree relatively well with observations (e.g., Horwath et al., 2012; Medley et al., 2013). The magnitude and trend of the simulated future Antarctic climate change also agree well with earlier published results (Ligtenberg et al., 2013). Combined, this gives confidence that the presented variations and future changes in Antarctic FAC are realistic despite the use of a semi-empirical FDM.

\section{Conclusions}

The amount of air in the Antarctic firn layer greatly varies in time and space. Knowledge of these variations is critical for a correct interpretation of satellite measurements of surface height changes. FAC has often been estimated using a steadystate solution, thereby assuming that the firn layer density is constant in time. This approach does not consider temporal variations in FAC due to climate variability, nor the effect of meltwater refreezing on firn density and air content. Here, we examined the temporal variations in Antarctic FAC and assessed the differences with an earlier-published steady-state solution. Also, a transient simulation of the firn layer until 2200 is performed to estimate the effect of a warmer and wetter Antarctic climate on the FAC.

Averaged over the ice sheet, there is virtually no difference in average FAC between the steady-state and the timedependent solution. However, regional differences are quite large. In the part of the AIS, where no surface melt occurs $(\sim 90 \%)$, the FAC is slightly underestimated $(\sim 3 \%)$ by the steady-state solution. For coastal locations, where summer melt is significant, the steady-state solution overestimates the FAC, because refrozen meltwater that occupies firn pore space is not taken into account. A major application of FAC values is to correct ice-thickness measurements at the grounding line, in order to determine ice discharge from the ice sheet. Most of the grounding line is located in the low-elevation regions where melt occurs, indicating that the discharge of grounded ice is underestimated when steady-state FAC values are used. Between the steady-state and time-dependent models, the average FAC difference at the grounding line is $2.7 \mathrm{~m}$, which is $0.7 \%$ of the local ice thickness. Differences in ice thickness are, however, directly translated into differences in ice discharge and ice-sheet mass balance. Since the latter is a relatively small number, the influence of the FAC difference is quite significant $(23.5 \%$ or
16.7 $\mathrm{Gt} \mathrm{yr}^{-1}$ ) when estimating the sea-level contribution of the AIS.

Seasonal and inter-annual variations in accumulation and temperature introduce short-term variability in FAC. In the East Antarctic interior, these variations are small $(<1 \%)$, due to low accumulation rates and low temperatures. Along the warmer and wetter coastal margins however, variations are larger $(\sim 5 \%)$. At locations with significant summer melt (e.g., coastal ice shelves), temporal FAC variations in the contemporary climate simulation can be as large as $50 \%$. Elsewhere, the FAC variations are predominantly caused by variability in accumulation.

In the future, the largest part of the AIS will remain meltfree, resulting in a FAC increase due to an accumulation increase. This increase is partly counteracted by an increase in firn compaction and the faster transition from firn to ice at the bottom of the firn layer. At the highest altitudes, the smallest relative increase (2200-2000) is simulated (4\%), while at moderate altitudes (1000-2000 m) a FAC increase of 12$14 \%$ is simulated. At the lowest altitudes (generally below $500 \mathrm{~m}$ ), this effect is partly or fully compensated by the increase in surface melt. The ice shelves in West Antarctica, the Antarctic Peninsula, and Dronning Maud Land lose most of their FAC due to this process and therewith their buffer capacity to refreeze meltwater.

The simulated future increase in FAC indicates that, in addition to a mass increase due to increased accumulation (Ligtenberg et al., 2013), the volume of the AIS will increase at a rate of $\sim 300 \mathrm{~km}^{3} \mathrm{yr}^{-1}$. Interpreting this as a change in ice mass would lead to an underestimation of the contribution of the AIS to sea-level rise. Corrections for variations in the firn layer are therefore crucial for a correct interpretation of future AIS volume changes and their conversion to mass changes.

Acknowledgements. We thank Rob Arthern, Ghislain Picard and one anonymous reviewer for their time and constructive comments. This work was supported by the Netherlands Polar Program of NWO/ALW and the ice2sea project, funded by the European Commission's 7th Framework Programme, grant number 226375 , ice2sea manuscript No. 172.

Edited by: M. Schneebeli 


\section{References}

Arthern, R. J., Vaughan, D. G., Rankin, A. M., Mulvaney, R., and Thomas, E. R.: In situ measurements of Antarctic snow compaction compared with predictions of models, J. Geophys. Res., 115, doi:10.1029/2009JF001306, 2010.

Barnola, J.-M., Pimienta, P., Raynaud, D., and Korotkevich, Y. S.: $\mathrm{CO}_{2}$-climate relationship as deduced from the Vostok ice core: a re-examination based on new measurements and on a re-evaluation of the air dating, Tellus, 43B, 83-90, doi:10.1034/j.1600-0889.1991.t01-1-00002.x, 1991.

Bromwich, D. H., Nicolas, J. P., and Monaghan, A. J.: An Assessment of Precipitation Changes over Antarctica and the Southern Ocean since 1989 in Contemporary Global Reanalyses, J. Climate, 24, 4189-4209, doi:10.1175/2011JCLI4074.1, 2011.

Das, I., Bell, R. E., Scambos, T. A., Wolovick, M., Creyts, T. T., Studinger, M., Frearson, N., Nicolas, J. P., Lenaerts, J. T. M., and van den Broeke, M. R.: Influence of persistent wind-scour on surface mass balance of Antarctica, Nat. Geosci., 6, 367-371, doi:10.1038/ngeo1766, 2013.

Davis, C. H., Li, Y., McConnell, J. R., Frey, M. M., and Hanna, E.: Snowfall-driven growth in East Antarctic ice sheet mitigates recent sea-level rise, Science, 308, 1898-1901, doi:10.1126/science.1110662, 2005.

Depoorter, M. A., Bamber, J. L., Griggs, J. A., Lenaerts, J. T. M., Ligtenberg, S. R. M., van den Broeke, M. R., and Moholdt, G.: Calving fluxes and melt rates of Antarctic ice shelves, Nature, 502, 89-92, doi:10.1038/nature12567, 2013.

Fretwell, P., Pritchard, H. D., Vaughan, D. G., Bamber, J. L., Barrand, N. E., Bell, R., Bianchi, C., Bingham, R. G., Blankenship, D. D., Casassa, G., Catania, G., Callens, D., Conway, H., Cook, A. J., Corr, H. F. J., Damaske, D., Damm, V., Ferraccioli, F., Forsberg, R., Fujita, S., Gim, Y., Gogineni, P., Griggs, J. A., Hindmarsh, R. C. A., Holmlund, P., Holt, J. W., Jacobel, R. W., Jenkins, A., Jokat, W., Jordan, T., King, E. C., Kohler, J., Krabill, W., Riger-Kusk, M., Langley, K. A., Leitchenkov, G., Leuschen, C., Luyendyk, B. P., Matsuoka, K., Mouginot, J., Nitsche, F. O., Nogi, Y., Nost, O. A., Popov, S. V., Rignot, E., Rippin, D. M., Rivera, A., Roberts, J., Ross, N., Siegert, M. J., Smith, A. M., Steinhage, D., Studinger, M., Sun, B., Tinto, B. K., Welch, B. C., Wilson, D., Young, D. A., Xiangbin, C., , and Zirizzotti, A.: Bedmap2: improved ice bed, surface and thickness datasets for Antarctica, The Cryosphere, 7, 375-393, doi:10.5194/tc-7-3752013, 2013.

Harper, J., Humphrey, N., Pfeffer, W. T., Brown, J., and Fettweis, X.: Greenland ice-sheet contribution to sea-level rise buffered by meltwater storage in firn, Nature, 491, 240-243, doi:10.1038/nature11566, 2012.

Helsen, M. M., van den Broeke, M. R., van de Wal, R. S. W., van de Berg, W. J., van Meijgaard, E., Davis, C. H., Li, Y., and Goodwin, I.: Elevation changes in Antarctica mainly determined by accumulation variability, Science, 320, 1626-1628, doi:10.1126/science.1153894, 2008.

Herron, M. and Langway, C.: Firn densification: an empirical model, Journal of Glaciology, 25, 373-385, 1980.

Holland, P. R., Corr, H. F. J., Pritchard, H. D., Vaughan, D. G., Arthern, R. J., Jenkins, A., and Tedesco, M.: The air content of Larsen C Ice Shelf, Geophys. Res. Lett., 38, doi:10.1029/2011GL047245, 2011.
Horwath, M., Legresy, B., Remy, F., Blarel, F., and Lemoine, J.M.: Consistent patterns of Antarctic ice sheet interannual variations from ENVISAT radar altimetry and GRACE satellite gravimetry, Geophys. J. Int., 189, 863-876, doi:10.1111/j.1365246X.2012.05401.x, 2012.

Kaspers, K. A., van der Wal, R. S. W., van den Broeke, M. R., Schwander, J., van Lipzig, N. P. M., and Brenninkmeijer, C. A. M.: Model calculations of the age of firn air across the Antarctic continent, Atmos. Chem. Phys., 4, 1817-1853, doi:10.5194/acp-4-1365-2004, 2004.

Kuipers Munneke, P., Picard, G., van den Broeke, M. R., Lenaerts, J. T. M., and van Meijgaard, E.: Insignificant change in Antarctic snowmelt volume since 1979, Geophys. Res. Lett., 39, doi:10.1029/2011GL050207, 2012.

Kuipers Munneke, P., Ligtenberg, S. R. M., van den Broeke, M. R., and Vaughan, D. G.: Firn air depletion as a precursor for Antarctic ice-shelf collapse, J. Glaciol., 60, 205-214, doi:10.3189/2014JoG13J183, 2014.

Lenaerts, J. T. M., van den Broeke, M. R., van de Berg, W. J., van Meijgaard, E., and Kuipers Munneke, P.: A new, high-resolution surface mass balance map of Antarctica (1979-2010) based on regional atmospheric climate modeling, Geophys. Res. Lett., 39, doi:10.1029/2011GL050713, 2012.

Ligtenberg, S. R. M., Helsen, M. M., and van den Broeke, M. R.: An improved semi-empirical model for the densification of Antarctic firn, The Cryosphere, 5, 809-819, doi:10.5194/tc-5-809-2011, 2011.

Ligtenberg, S. R. M., Horwath, M., van den Broeke, M. R., and Legrésy, B.: Quantifying the seasonal 'breathing' of the Antarctic ice sheet, Geophys. Res. Lett., 39, doi:10.1029/2012GL053628, 2012.

Ligtenberg, S. R. M., van de Berg, W. J., van den Broeke, M. R., Rae, J. G. L., and van Meijgaard, E.: Future surface mass balance of the Antarctic ice sheet and its influence on sea level change, simulated by a regional atmospheric climate model, Climate Dynam., 41, 867-884, doi:10.1007/s00382-013-1749-1, 2013.

Marsh, P. and Woo, M.-K.: Wetting front advance and freezing of meltwater within a snow cover 1 . observation in the Canadian Arctic, Water Resource Research, 20, 1853-1864, doi:10.1029/WR020i012p01853, 1984.

Martinerie, P., Lipenkov, V. Y., Raynaud, D., Chappellaz, J., Barkov, N. I., and Lorius, C.: Air content paleor ecord in the Vostok ice core (Antarctica): A mixed record of climatic and glaciological parameters, J. Geophys. Res., 99, 10565-10576, doi:10.1029/93JD03223, 1994.

Medley, B., Joughin, I., Das, S. B., Steig, E. J., Conway, H., Gogineni, S., Criscitiello, A. S., McConnell, J. R., Smith, B. E., van den Broeke, M. R., Lenaerts, J. T. M., Bromwich, D. H., and Nicolas, J. P.: Airborne-radar and ice-core observations of annual snow accumulation over Thwaites Glacier, West Antarctica confirm the spatiotemporal variability of global and regional atmospheric models, Geophys. Res. Lett., 40, 1-6, doi:10.1002/grl.50706, 2013.

Monaghan, A. J., Bromwich, D. H., Fogt, R. L., Wang, S.-H., Mayewski, P. A., Dixon, D. A., Ekaykin, A., Frezzotti, M., Goodwin, I., Isaksson, E., Kaspari, S. D., Morgan, V. I., Oerter, H., Van Ommen, T. D., Van der Veen, C. J., and Wen, J.: Insignificant Change in Antarctic Snowfall Since the Int. Geophys. Year, Sci., 313, 827-831, doi:10.1126/science.1128243, 2006. 
Monaghan, A. J., Bromwich, D. H., Chapman, W., and Comiso, J. C.: Recent variability and trends of Antarctic near-surface temperature, J. Geophys. Res., 113, doi:10.1029/2007JD009094, 2008.

Peltier, W. R.: Global glacial isostasy and the surface of the ice-age earth: The ICE-5G (VM2) Model and GRACE, Annu. Rev. Earth Planet. Sci., 32, 111-149, doi:10.1146/annurev.earth.32.082503.144359, 2004.

Pritchard, H. D., Ligtenberg, S. R. M., Fricker, H. A., Vaughan, D. G., van den Broeke, M. R., and Padman, L.: Antarctic icesheet loss driven by basal melting of ice shelves, Nature, 484, 502-505, doi:10.1038/nature10968, 2012.

Rignot, E. and Jacobs, S. S.: Rapid bottom melting widespread near Antarctic ice sheet grounding lines, Science, 296, doi:10.1126/science.1070942, 2002.

Rignot, E., Bamber, J. L., van den Broeke, M. R., Davis, C., Li, Y., van de Berg, W. J., and van Meijgaard, E.: Recent Antarctic ice mass loss from radar interferometry and regional climate modelling, Nat. Geosci., 1, 106-110, doi:10.1038/ngeo102, 2008.

Rignot, E., Velicogna, I., van den Broeke, M. R., Monaghan, A., and Lenaerts, J. T. M.: Acceleration of the contribution of the Greenland and Antarctic ice sheets to sea level rise, Geophys. Res. Lett., 38, doi:10.1029/2011GL046583, 2011.

Rignot, E., Jacobs, S., Mouginot, J., and Scheuchl, B.: Ice shelf melting around Antarctica, Science, 341, 266-270, doi:10.1126/science.1235798, 2013.

Scambos, T. A., Frezzotti, M., Haran, T., Bohlander, J., Lenaerts, J. T. M., van den Broeke, M. R., Jezek, K., Long, D., Urbini, S., Farness, K., Neumann, T., Albert, M., and Winther, J.-G.: Extent of low-accumulation 'wind glaze' areas on the East Antarctic plateau: implications for continental ice mass balance, J. Glaciol., 58, 633-647, doi:10.3189/2012JoG11J232, 2012.

Shepherd, A., Ivins, E. R., Geruo, A., and IMBIE project group: A Reconciled Estimate of Ice-Sheet Mass Balance, Science, 338, 1183-1189, doi:10.1126/science.1228102, 2012.

Sørensen, L. S., Simonsen, S. B., Nielsen, K., Lucas-Picher, P., Spada, G., Adalgerisdottir, G., Forsberg, R., and Hvidberg, C. S.: Mass balance of the Greenland ice sheet (2003-2008) from ICESat data - the impact of interpolation, sampling and firn density, The Cryosphere, 5, 173-186, doi:doi:10.5194/tc-5-1732011, 2011.
Spencer, M. K., Alley, R. B., and Creyts, T. T.: Preliminary firndensification model with 38-site dataset, J. Glaciol., 47, 671-676, doi:10.3189/172756501781831765, 2001.

Van de Berg, W. J., van den Broeke, M. R., Reijmer, C. H., and van Meijgaard, E.: Reassessment of the Antarctic surface mass balance using calibrated output of a regional atmospheric climate model, J. Geophys. Res., 111, doi:10.1029/2005JD006495, 2006.

Van den Broeke, M. R.: Depth and Density of the Antarctic firn layer, Arctic, Antarc. Alp. Res., 40, 432-438, doi:10.1657/15230430(07-021)[BROEKE]2.0.CO;2, 2008.

Van den Broeke, M. R., van de Berg, W. J., and van Meijgaard, E.: Snowfall in coastal West Antarctica much greater than previously assumed, Geophys. Res. Lett., 33, doi:10.1029/2005GL025239., 2006.

Van den Broeke, M. R., van de Berg, W. J., and van Meijgaard, E.: Firn depth correction along the Antarctic grounding line, Antarc. Sci., 20, 513-517, doi:10.1017/S095410200800148X, 2008.

Van Meijgaard, E., van Ulft, L. H., van de Berg, W. J., Bosveld, F. C., van den Hurk, B. J. J. M., Lenderink, G., and Siebesma, A. P.: The KNMI regional atmospheric climate model RACMO version 2.1, Royal Netherlands Meteorological Institute, De Bilt, The Netherlands, 2008.

Velicogna, I.: Increasing rates of ice mass loss from the Greenland and Antarctic ice sheets revealed by GRACE, Geophys. Res. Lett., 36, doi:10.1029/2009GL040222, 2009.

Wever, N., Fierz, C., Mitterer, C., Hirashima, H., and Lehning, M.: Solving Richards Equation for snow improves snowpack meltwater runoff estimations in detailed multi-layer snowpack model, The Cryosphere, 8, 257-274, doi:10.5194/tc-8-257-2014, 2014.

Whitehouse, P. L., Bentley, M. J., and Brocq, A. M. L.: A deglacial model for Antarctica: geological constraints and glaciological modelling as a basis for a new model of Antarctic glacial isostatic adjustment, Quat. Sci. Rev., 32, 1-24, doi:10.1016/j.quascirev.2011.11.016, 2012.

Zwally, H. J. and Giovinetto, M. B.: Overview and Assessment of Antarctic Ice-Sheet Mass Balance Estimates: 1992-2009, Surv Geophys., 32, 351-376, doi:10.1007/s10712-011-9123-5, 2011.

Zwally, H. J. and Li, J.: Seasonal and interannual variations of firn densification and ice-sheet surface elevation at the Greenland Summit, J. Glaciol., 48, 199-207, doi:10.3189/172756502781831403, 2002. 